\title{
Weibull Probabilistic Model of Moisture Concentration Build Up in a Fiber Graphite/Epoxy Polymer Composite under Varying Hydrothermal Conditions
}

\author{
Boucham Belhadj ${ }^{1}$, Lousdad Abdelkader $^{1 *}$, Alaa Chateauneuf² \\ 1 Laboratory of Mechanics of Structures and Solids (LMSS), Department of Mechanical Engineering, Faculty of Technology, \\ University Djilali Liabes of Sidi Bel-abbes, 22000 Sidi Bel-abbes, Cité Ben M'Hidi, P. O. B. 89, Algeria \\ 2 Polytech Clermont-Ferrand, Université Clermont Auvergne, 63100 Aubière, 2 Blaise Pascal Avenue, France \\ * Corresponding author, e-mail: a_lousdad@yahoo.com
}

Received: 27 December 2018, Accepted: 13 October 2020, Published online: 21 December 2020

\begin{abstract}
Advanced mechanical and structural applications require accurate assessment and better knowledge of the damage state during elaboration and service. The development of life prediction methodologies for Glass Fiber Reinforced Polymers (GFRPs) has increased with the use of composites in different industries. It is important to develop through thickness degradation analyses due to ageing in order to predict its effect on the lifetime of composite structures. This study aims to model the moisture absorption, the concentration of the absorbed fluid and the reduction of mechanical properties in the through the thickness direction of a GFRPs structure. The water absorption behavior of woven glass fiber reinforced cyanate ester composites used in the plenum of the air conditioning pack of aircraft environmental control system has been modeled. The combined models describe the diffusion procedure primarily at material level and continuously at structure level. The amount of the absorbed moisture can be crucial for the mechanical behavior of the structure. Therefore, there is a need for a better understanding of the evolution of mechanical properties during ageing. The procedure utilizes the results of the diffusion model to calculate the moduli degradation during the water uptake process. Predictive models have been proposed by considering different sections throughout the thickness and provide a solid background for modeling the long term behavior of a structure exposed at different temperature and different time period. This work performed the numerical studies on the effect of moisture, temperature and presents some useful instructions for the evaluation of such composite structures.
\end{abstract}

\section{Keywords}

moisture absorption, ageing process of composites, module degradation, modelling of ageing process, life time prediction

\section{Introduction}

The fibrous composite materials with polymer matrix replace more and more metals in many industrial sectors. Application includes aerospace, automotive, construction, marine goods, sporting goods and infrastructure. In general, for higher performance composite materials are used where high strength and stiffness along with light weight and corrosion resistance are required such as in airplane and aerospace engineering where the high mechanical properties and the low density are the main determinant factors. The elements of fuselage, rudders and plane wings are examples of components designed from composite materials. Their utilization is expanded to the infrastructure industry, marine industry, and the offshore oil industry all of which require composite materials to endure harsh moisture and temperature environments. However, special care is considered when introducing progressively new composite materials in industry because of the difficulty to predict their lifespan. The long-term behavior of composites becomes as much randomly as they are subjected to external mechanical loading and exposed to climatic conditions (temperature and moisture). Indeed, the hygrothermal stability is mandatory for the choice of the composite material type. The importance of this aspect on the safe use of structures motivated many research subjects in this field. Particular focus is to be given to reducing design uncertainties through a better understanding of material interaction with extreme and harsh service environment. Among many types of environment damage, the combined effect of temperature and moisture ingression is regarded as the most detrimental one [1,2]. 
In this regards, the composite material considered in this study belongs to the graphite/epoxy type. Specifically for its application and use in airplane, aerospace structures and car industries make it more exposed to environmental varying conditions and operational heating which can significantly contribute to the deterioration of the material and thus affect the structural integrity of the composite structure $[3,4]$. Generally, the composite structure is very complicated, and can significantly affect the moisture diffusion along the thickness direction. However, the adopted model seems very simple, and cannot reflect the role of microstructure.

\subsection{Effects of moisture}

Moisture is well known to affect negatively numerous properties of polymers and their composites. Considerable attention has been given by many researchers to address the effect of moisture on the mechanical behavior of polymers matrix composites since it is relevant to optimum design and to the effectiveness for structural applications. A good deal and extensive literature reviews exist characterizing the effect of temperature and moisture on static mechanical properties of carbon/epoxy composites. However, these effects vary between material systems and thus must be determined on an individual material basis. While the effects of moisture and temperature on composite properties and behavior have been studied extensively, the studies involving carbon fiber composite fatigue behavior have been limited in number and in scope. An extensive review of the literature pertaining to such topics can be found in [5-7].

\subsection{Effects of moisture/temperature interaction}

It is well known that temperature has an effect on composite mechanical properties. Matrix dominated mechanical properties decrease with increasing temperature. Fiberdominated properties are affected by cold temperature with less impact than those on matrix dominated at elevated temperature which may alter the design parameters.

The amount of absorbed moisture depends on the matrix material and relative humidity. Elevated temperature increase the rate of moisture absorption which results in reduction of the matrix material dominated mechanical properties due to matrix swelling. Parameters such as volume fraction of the fiber, nature of the resign system, temperatures, additives, fiber orientation, fiber surface coating, sizing and void volume affect the water diffusion in polymer matrix composites [8]. Various studies examine the effect of the moisture/temperature combination on composite tensile strength and modulus Davison [5]. Almen et al. [9, 10] presented results showing degradation of a variety of carbon fiber reinforced epoxy woven composite properties in hot/wet environments. Shen and Springer [11] found moisture related degradations in tensile strength and stiffness of 0 and $45^{\circ}$ carbon/epoxy composites to be independent of temperature. On the other hand, tensile properties of 90 laminates were significantly affected by moisture and temperature. Significant degradation in transverse strength of a carbon/ epoxy composite with moisture and temperature was also found by Shen and Springer [12], Boukhoulda et al. [13] and Mahmoudi et al. [14]. In order to study the moisture diffusion in composites with polymer matrix, the material is exposed to a controlled wet environment such as steam and water $[15,16]$. The main goal of these works is to evaluate the mechanical properties and the moisture concentration with respect to temperature and time. Several studies have considered the effect of environmental conditions on laminated plates [17]. Smith and Weitsman [18] noted that, for composites with polymer matrix immersed in sea water, there is an important difference between the moisture concentration in the matrix and in the fiber/matrix interface. Chamis et al. [19] proposed a general theory to obtain the response of hygro-thermo-mechanics of composites. Kriz and Stinchcomb [20] showed to what extent the absorptive moisture modifies the state of stresses as well as the damage process at the laminated edges under static tensile stress or cyclic loading. In the work carried out by Bradley and Grant [21] the effect of sea water on the composite interface has been considered. It was noted that a reduction in the shear strength is due to the moisture absorption. Also, various studies had considered the combined effect of temperature and humidity on the tensile strength and the modulus of elasticity [3, 22]. The results obtained by Almen et al. [9, 10] have shown a degradation of various properties of carbon reinforced epoxy composites in heating/cooling environments. Significant deterioration in shear strength of carbon/epoxy composite under moisture and temperature was also found by Browning et al. [23]. Vaddadi et al. [24] have evaluated the effect of moisture absorption for composite materials subjected to wet environment, and gave detailed numerical analyses which simulate the real heterogeneous microstructures of the composite. Therefore, it is mandatory to build a comprehensive knowledge of composite materials subjected to severe and complex cyclic environmental 
conditions which has been highlighted in several works. The models of the Fickian diffusion have been verified by experimental data on moisture absorption for graphite/epoxy composites and epoxy glass [25]. The combined effect of moisture and temperature became increasingly dangerous when cyclic environmental conditions exist. Consequently, the hygrothermal stresses due to the effect of the cyclic environment seem to be considerably important for the design which is of practical interest.

In the present work, a numerical model is built for the prediction of moisture diffusion under cyclic environmental conditions based on the classical assumptions for non-uniform transient concentration as described by Adda-Bedia et al. [26, 27] and Verchery [28]. This model is then applied to evaluate the scatter of the moisture concentration in terms of input parameter uncertainties especially for material diffusivity. It is shown that the moisture distribution is far from being normally distributed. Thus extreme distributions should be considered to better represent the scatter of the graphite/epoxy moisture concentration. This result is very useful for reliability analysis of composite plates under climatic conditions.

\subsection{Fick's model for water absorption}

The polymers have very good characteristics at the beginning of service. However, they are very sensitive to the environmental conditions during the service life due to the wet ageing which deteriorates their physical and mechanical properties. Actually the study of this wet ageing constitutes an important field of research in order to allow accurate prediction of the rate of material damage evolution and its upper limit for safe use. The long time exposure of a composite to a wet environment can have serious consequences on its mechanical and physical properties since water infiltrates in the composite by diffusion and attacks the chemical structure of the composite matrix. Although the temperature effects have been studied for a long time and are therefore well modeled, the moisture effects are rather difficult to take into account because of the high dependence on the structure and the molecular morphology of polymers. Indeed, the characterization of the hygro-mechanical behavior of polymers and composites is dealt with in a low number of studies compared to the thermo-mechanical behavior of these materials. Under ageing effects the composite materials present two weak aspects pertaining to temperature and humidity. When the stability is subjected to the combined increase of temperature and hygroscopy the matrices as well as the fiber/ matrix interface present inherent hydraulic brittleness.
The deterioration of composites is initiated by a phenomenon of plasticization known as physical ageing which results from the water diffusion within the polymer matrix and/or within the fiber/matrix interface. Therefore, the analysis of time-dependent water absorption for composite materials is mandatory since absorption simultaneously depends on the nature of components, temperature and relative humidity [29]. Under the effect of moisture higher water absorption can lead to a hygroscopic dilatation in the laminate. Under normal operating temperatures this phenomenon is reversible; i.e. after drying, the material restores its initial properties. Nevertheless, certain molecules remain trapped and are difficult to eliminate due to the hydrogen bonds with the polymer [30]. From another point of view, the increase of temperature amplifies the natural vibrations of the molecular structure causing a thermal dilatation and a plasticization of the material. As long as the threshold temperature is not reached these phenomena are reversible. Beyond a certain limit of temperature and moisture other mechanisms can be involved causing a swelling or a plasticization of the resin [31, 32]. Numerous diffusion models have been proposed to study moisture diffusion into various composites under different external hygrothermal conditioning. One dimensional Fick's law is the most frequently used one by researchers to investigate moisture diffusion behavior into single-fiber-reinforced composites [17]. Fick's law describes the water diffusion in a medium presenting a concentration gradient. It presents a linear relationship between the diffusing flow through a plane surface of infinite size compared to the thickness and the second derivative of the concentration with respect to the normal direction. The Fickian diffusion is characterized by two parameters respectively the diffusion coefficient $D$ (independent of time and space) and the moisture concentration $C$. For the considered plates, the water diffusion within the composite is well described by Fick's second law where the solution is determined by a numerical incremental procedure based on step-by-step time integration [33]. As for thin plates the diffusion is carried out according to only one direction (i.e. through the plate thickness) and Fick's second law takes the form:

$$
\frac{\partial C}{\partial t}=D_{x} \frac{\partial^{2} C}{\partial x^{2}},
$$

where $C$ is the moisture concentration, $D_{x}$ is the plate diffusivity in the $x$-direction and $t$ is the time. In our case, this equation is subjected to the following boundary conditions: 
$C(x, 0)=0$ for $0 \leq x \leq h$,

$C(0, t)=c 1$ and $C(h, t)=c 2$ for $t>0$.

Crank [34] presented a mathematical solution for Eq. (1) under different geometrical and boundary conditions. In a thin plate with thickness $h$ and initial concentration $C_{i}$, where the surfaces are kept under uniform concentration $C_{\infty}$ (water concentration at saturation), the concentration is given by:

$$
\begin{aligned}
& \frac{C-C_{i}}{C_{\infty}-C_{i}}= \\
& 1-\frac{4}{\pi} \sum_{n=0}^{\infty} \frac{(-1)^{n}}{2 n+1} \cos \frac{(2 n+1) \pi x}{h} \exp \left[-\frac{D_{x}(2 n+1)^{2} \pi^{2} t}{h^{2}}\right],
\end{aligned}
$$

with:

$$
\begin{aligned}
& D_{x}=D A 1 \cdot e^{-D A 2 / T}, \\
& C_{\infty}=C C 1 . H^{C C 2},
\end{aligned}
$$

where $H$ is the relative humidity (\%), DA1 is the permeability index $\left(\mathrm{mm}^{2} / \mathrm{S}\right), D A 2$ is the specific constant of the material $\left({ }^{\circ} \mathrm{K}\right), C C 1$ and $C C 2$ are dimensionless material constants. To obtain the total water mass in the composite Springer [15] integrated Eq. (7) on the plate thickness leading to:

$$
\begin{aligned}
& G=\frac{m-m_{i}}{m_{\infty}-m_{i}}= \\
& 1-\frac{8}{\pi^{2}} \sum_{n=0}^{\infty} \frac{1}{(2 n+1)^{2}} \exp \left[-\frac{D_{x}(2 n+1)^{2} \pi^{2} t}{h^{2}}\right],
\end{aligned}
$$

where $G$ is the mass fraction of absorptive water, $m$ is the absorptive water mass at the time $t, m_{\propto}$ is the absorptive water mass at saturation and $m_{i}$ is the initial water mass in the composite.

\section{Water absorption in the studied plates}

In this work graphite/epoxy plates of type T300/5208 subjected to cyclic environmental actions of temperature and moisture applied on both faces are investigated (Fig. 1). Three plate thicknesses have been considered: $4.8,8.8$ and $13.8 \mathrm{~mm}$. The characteristics of the T300/5208 are given in Table $1[25,29]$.

A typical cycle of the applied temperature and relative humidity is illustrated in Fig. 2 (a) and (b).

For a period of 144 hours, the temperature varies from $27^{\circ} \mathrm{C}$ to $65^{\circ} \mathrm{C}$ with a last heating at $142{ }^{\circ} \mathrm{C}$ while the relative humidity oscillates between $14 \%$ and $82 \%$. These cycles

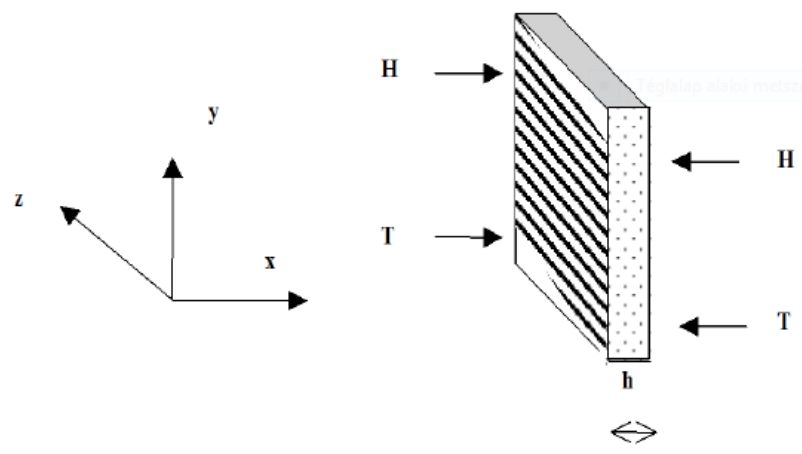

Fig. 1 Plate subjected to temperature and moisture in the $\mathrm{x}$-axis direction

Table 1 Characteristics of the T300/5208 material

\begin{tabular}{lccccc}
\hline$\rho\left(\mathrm{Kg} / \mathrm{m}^{3}\right)$ & $C_{\infty}$ & $D A 1\left(\mathrm{~mm}^{2} / \mathrm{S}\right)$ & $D A 2\left({ }^{\circ} \mathrm{K}\right)$ & $C C 1$ & $C C 2$ \\
\hline 1600 & 1.23 & 0.57 & 4993 & 0.015 & 1 \\
\hline
\end{tabular}

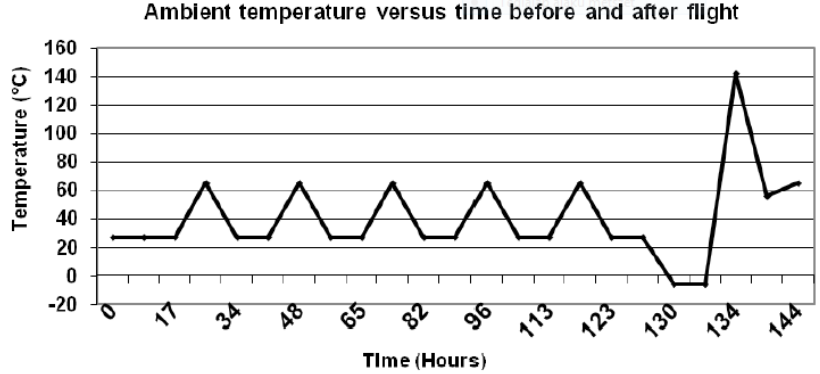

(a)

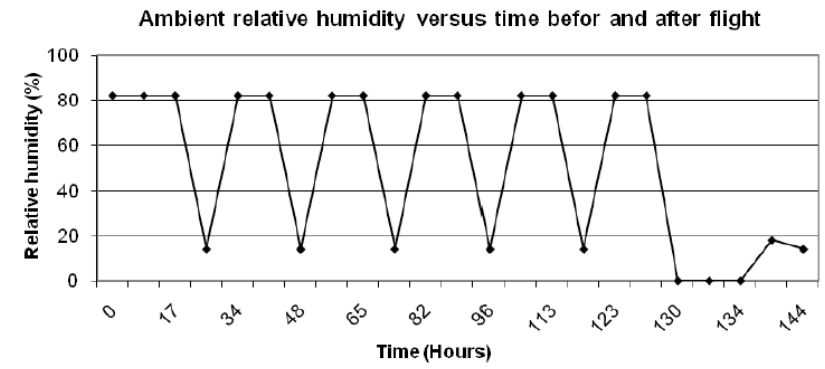

(b)

Fig. 2 Applied environmental temperature and relative humidity cycles (a) Ambient temperature versus time before and after flight; (b) Ambient relative humidity versus time before and after flight

correspond to a flight testing as described by Springer [15]. This plane test simulates temperature and moisture variations during 123 hours in normal atmospheric conditions followed by 11 hours of flight and finally 10 hours of normal atmospheric conditions. In the test the ambient relative humidity is increased when temperature is decreased except during the flight where moisture becomes zero. It can also be noticed that the high relative humidity is kept at $82 \%$. The studied plates are exposed to 2000 cycles of 144 hours each as described in Fig. 2 which is equivalent to nearly 33 years. The diffusion analysis aims to compute the moisture concentration through the plate thickness 
with respect to time. This can be carried out by numerical integration of Fick's law for water absorption in composite plates as described in the above section and as reported in [35-37]. For cycles with lower temperature levels: 27, 37 and $47{ }^{\circ} \mathrm{C}$, Fig. 3 shows the moisture concentration in graphite/epoxy plates subjected to the relative humidity cycles indicated previously in Fig. 2 (b).

It can be observed that at the first stage the water absorption increases monotonically until saturation where the increase of weight is fast and regular. The second stage is rather constant which indicates a "quasi-nil" diffusion. The moisture concentration curves present an inflection point which is more visible for thick plates. After an initial acceleration the moisture rate is almost linear (up to $40 \%$ of the saturation moisture at temperature $47{ }^{\circ} \mathrm{C}$ $" h=4.8 \mathrm{~mm}$ ). Then the water absorption rate decreases progressively until the maximum moisture saturation. From these curves it can be observed that higher temperature increases proportionally the moisture concentration. In addition to the diffusivity increase (slope of the curve) the long-term water concentration increases with temperature ranging from $0.61 \%$ at $37{ }^{\circ} \mathrm{C}$ to $0.71 \%$ at $47{ }^{\circ} \mathrm{C}$ for

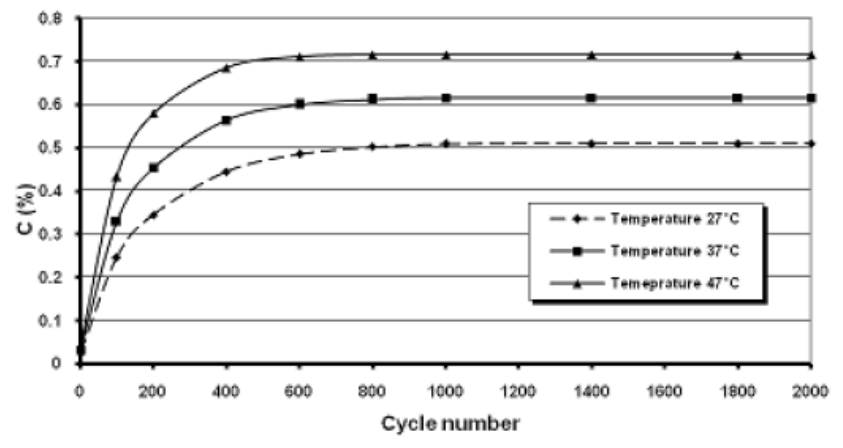

(a)

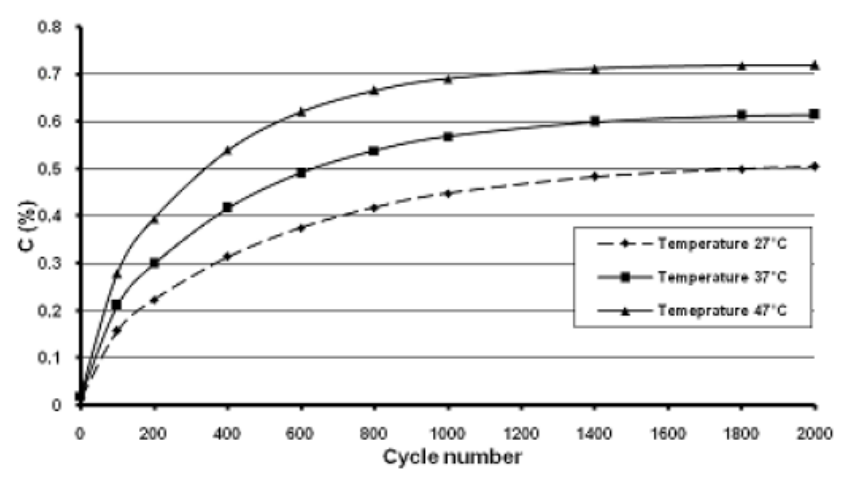

(b)

Fig. 3 Moisture concentration as a function of cycles; (a) Variation of average humidity concentration versus number of cycles $(e=8.8 \mathrm{~mm})$; (b) Variation of average humidity concentration versus number of cycles $(e=13.8 \mathrm{~mm})$ $h=4.8 \mathrm{~mm}$ (i.e. $10 \%$ of increase). This is explained by the temperature activation of the diffusion process.

For $h=8.8 \mathrm{~mm}$ the influence of temperature is visible in reducing the time to saturation: at $47{ }^{\circ} \mathrm{C}$ the material is saturated at 1000 cycles (i.e. 17 years) while at $27^{\circ} \mathrm{C}$, saturation occurs at 800 cycles (i.e. 13 years). Concerning the saturation level, it is $0.51 \%$ at $27{ }^{\circ} \mathrm{C}, 0.61 \%$ at $37{ }^{\circ} \mathrm{C}$ and $0.71 \%$ at $47{ }^{\circ} \mathrm{C}$ respectively. We can conclude that the moisture concentration is around $0.61 \%$, which can be expressed as the limit concentration increase with time and that diffusivity increases with temperature. For cycles with lower temperature of $37{ }^{\circ} \mathrm{C}$, Fig. 4 illustrates the moisture concentration for the three plate thicknesses as a function of loading cycles.

It can be observed that for the studied material the moisture concentration does not exceed $0.61 \%$ whatever the ageing time is. Although that concentration curves converges to the limit value of $0.61 \%$, the necessary time to reach this limit depends strongly on the plate thickness. It is respectively equal to 200, 600 and 1500 cycles for thickness of 4.8, 8.8 and $13.8 \mathrm{~mm}$. The relationship between saturation time and thickness is thus strongly nonlinear. In the following probabilistic analysis the simulations are carried out till 2000 cycles in order to guarantee that saturation is reached especially for the small plate thickness (i.e. $4.8 \mathrm{~mm}$ ).

\subsection{Propagation of model uncertainties}

In order to study the scatter of the moisture concentration, the Graphite/Epoxy plates, with $4.8 \mathrm{~mm}$ of thickness are subjected to 2000 cycles of $144 \mathrm{~h}$ as illustrated in Fig. 1. Although that saturation is observed at 600 cycles, the random sampling may lead to much larger saturation times as illustrated in Fig. 5.

For this reason 2000 cycles have been chosen in order to be sure that saturation is reached in all the simulated configurations. The thermal conductivity is set to $402.2 \mathrm{~W} / \mathrm{m}^{\circ} \mathrm{K}$ and the parameters are taken as shown previously in Table 1.

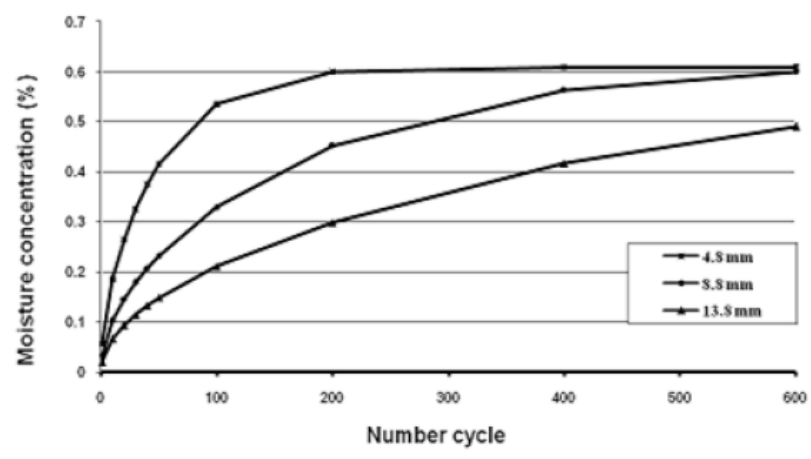

Fig. 4 Moisture concentration as a function of cycles 


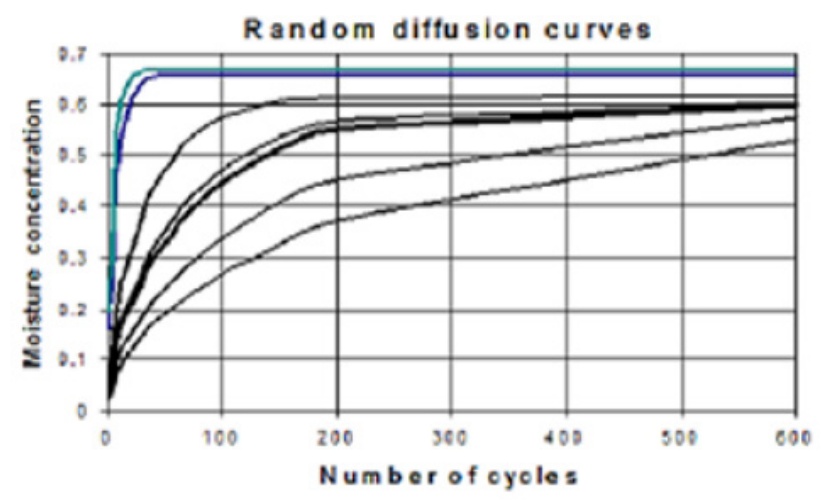

Fig. 5 Random sampling of moisture as a function of exposure time

The distribution of moisture concentration is determined by performing Monte Carlo simulations on the diffusion model. For each random sample, the incremental diffusion model is applied in order to determine the response in terms of moisture concentration. Fig. 5 shows an example of some random samples.

The input model uncertainties are considered by assuming normally distributed random variables with a given Coefficient Of Variation (COV). In this study the randomness is considered for the parameters $D A 1$ and $D A 2$, as well as for the plate thickness.

For each configuration one thousand random simulations have been carried out leading to one thousand realizations of the moisture concentration. The statistical analysis of the response allows us to determine the influence of each parameter on the concentration scatter.

\subsubsection{Moisture distribution}

For plates with thickness of $4.8 \mathrm{~mm}$ the Monte Carlo sampling is carried out according to the coefficients of variation indicated in Table 2 [38].

The observation of the moisture concentration parameters shows that the dispersion of the thickness and of the parameter $D A 1$ has no significant effect on the mean moisture concentration and very low effect on its standard deviation. Therefore, these parameters are not critical for material characterization. Within the considered range a small increase of the coefficient of variation of $D A 1$ decreases slightly the dispersion of the moisture concentration. This can be explained by the random compensation between $D A 1$ and $D A 2$ sampling. As it could be expected, the parameter $D A 2$ has a very large influence on the scatter of the moisture concentration. The present study shows also that this parameter influences strongly the shape of the moisture distribution which is mandatory for reliable design of such a plate. When the parameter COV varies from 0.01 to 0.07 (Table 2) the standard deviation of moisture is multiplied by a factor of 13 (i.e. from 0.0045 to 0.059 ). It can be noticed that the COV of the moisture concentration is almost proportional to the $\mathrm{COV}$ of $D A 2$. The observation of the distributions in Fig 6 (and the values of the kurtosis and the skeweness) shows that the distribution is evidently non-symmetrical with a very long lower tail. When the COV of DA2 increases from $4 \%$ to $5 \%$ the lower tail is significantly extended while the upper distribution tail remains almost constant.

This fact is very interesting for material reliability as high concentration probability is practically insensitive to material model uncertainties. This can be probably explained by the nonlinear action of the diffusion law. More generally this study shows that moisture cannot be represented by normal or lognormal distributions. The moisture concentration appears to follow an extreme value distribution. Fig. 7 shows the interaction effects for the three variables (i.e. thickness and diffusion parameters).

The comparison with Fig. 6 confirms that the thickness and the parameter $D A 1$ have an Uncertaitines: $c_{t}=2 \%$, $c_{D A 1}=7 \%, c_{D A 2}=7 \%$ very small effect on the moisture

Table 2 Influence of the parameter dispersion (thickness $=4.8 \mathrm{~mm}$ )

\begin{tabular}{lcccccc}
\hline $\begin{array}{l}\text { COV of } \\
\text { Thickness }\end{array}$ & $\begin{array}{c}\text { COV of } \\
D A 1\end{array}$ & $\begin{array}{c}\text { COV of } \\
D A 2\end{array}$ & Mean moisture & $\begin{array}{c}\text { Moisture Std } \\
\text { deviation }\end{array}$ & $\begin{array}{c}\text { Moisture } \\
\text { Kurstosis }\end{array}$ & $\begin{array}{c}\text { Moisture } \\
\text { Skewness }\end{array}$ \\
\hline 0.00 & 0.00 & 0.01 & 0.614 & 0.0045 & 0.41 & -0.26 \\
0.00 & 0.00 & 0.03 & 0.614 & 0.0154 & 1.08 & -0.72 \\
0.00 & 0.00 & 0.04 & 0.612 & 0.0245 & 6.15 & -1.83 \\
0.04 & 0.04 & 0.04 & 0.611 & 0.0238 & 3.63 & -1.41 \\
0.05 & 0.10 & 0.04 & 0.612 & 0.0231 & 3.15 & -1.31 \\
0.00 & 0.00 & 0.05 & 0.607 & 0.0371 & 6.49 & -2.14 \\
0.05 & 0.05 & 0.05 & 0.606 & 0.0356 & 3.47 & -1.51 \\
0.05 & 0.10 & 0.05 & 0.610 & 0.0330 & 5.80 & -1.92 \\
0.02 & 0.06 & 0.06 & 0.606 & 0.0453 & 7.38 & -2.31 \\
0.02 & 0.07 & 0.07 & 0.602 & 0.0590 & 8.09 & -2.51 \\
\hline
\end{tabular}




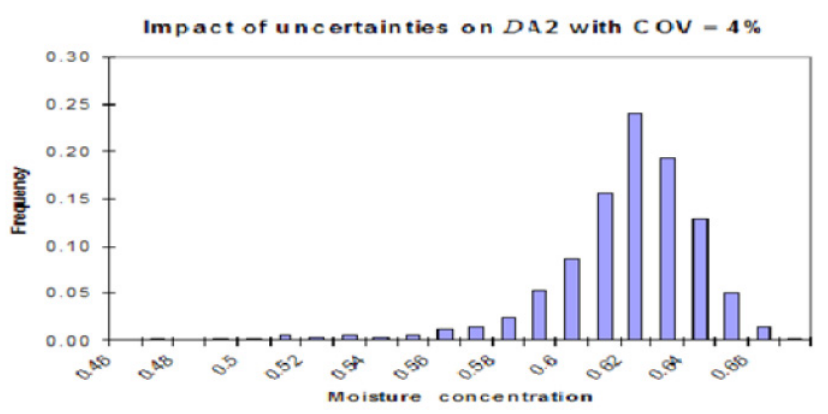

(a)

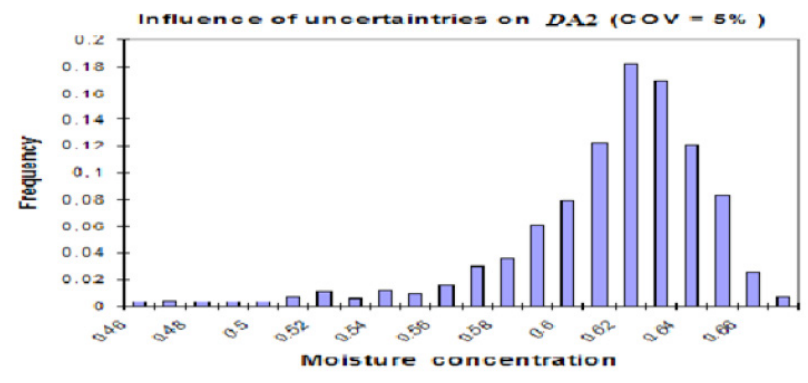

(b)

Fig. 6 Distribution of moisture concentration for different $\mathrm{COV}$ of $D A 2$; (a) Impact of uncertainties on $D A 2$ with $\mathrm{COV}=4 \%$; (b) Influence of uncertainties on $D A 2$ with $\mathrm{COV}=5 \%$

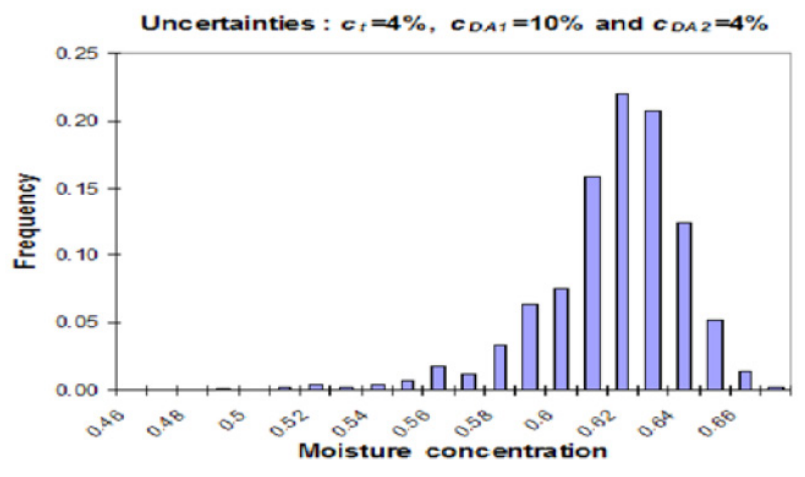

(a)

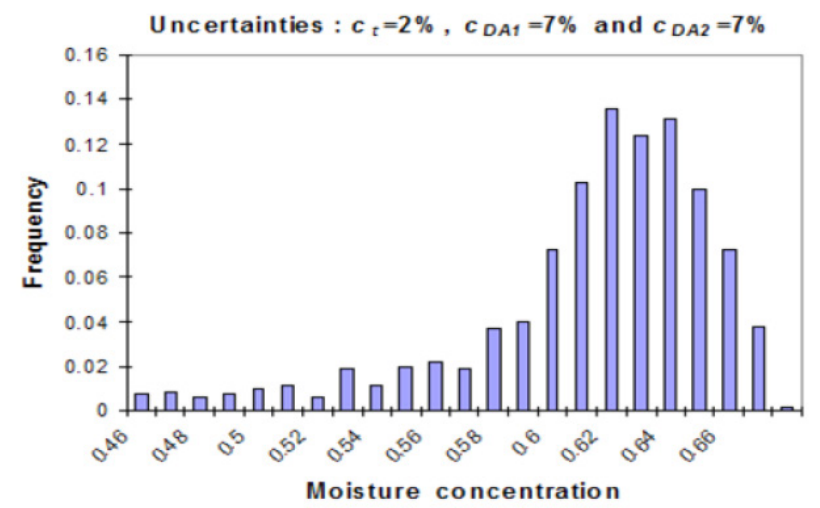

(b)

Fig. 7 Distribution of moisture concentration for different COV of $D \mathrm{~A} 2$; (a) Uncertaitines: $c_{t}=4 \%, c_{D A 1}=10 \%, c_{D A 2}=4 \%$; (b) Uncertaitines: $c_{t}=2$ $\%, c_{D A 1}=7 \%, c_{D A 2}=7 \%$ distribution. However, the increase of the COV of $D A 2$ from $4 \%$ to $7 \%$ leads to a very large distribution tail while the average is 0.602 . The minimum observed value becomes 0.25 for $7 \%$ of COV.

\section{Effects of the thickness}

The uncertainty analysis is now carried out for plates with thickness $8.8 \mathrm{~mm}$ and $13.8 \mathrm{~mm}$. The results are detailed in Tables 3 and 4 as well as in Fig. 8 .

The same trend is observed in these plates. However it can be seen that thick plates present larger COV of moisture than for thin plates. It is clearly shown form Table 3 that the skewness increases with the dispersion of $D A 2$ (the same trend is observed in Table 4 but with less significance). In parallel Fig. 8 shows that the scatter is much larger for thick plates $(13.8 \mathrm{~mm})$ where the dispersion is mainly in the direction of low moisture values i.e. more extended lower distribution tail.

\section{Probabilistic model}

According to the above results it can be recommended the same trend is observed in these plates. However it can be seen that thick plates present larger $\mathrm{COV}$ of moisture than for thin plates. It is clearly shown form Table 3 that the skewness increases with the dispersion of $D A 2$ (the same trend is observed in Table 4 but with less significance). In parallel Fig. 8 shows that the scatter is much larger for thick plates $(13.8 \mathrm{~mm})$ where the dispersion is mainly in the direction of low moisture values i.e. more extended lower distribution tail.

To model the moisture distribution by an extreme value by performing statistical tests for several distribution laws we have found that Weibull and Beta distributions are very suitable to represent the moisture scatter in graphite/epoxy plates. Table 5 gives the distribution parameters for the three considered thicknesses.

The beta distribution does not fit well the KolmogorovSmirnov's test. It gives a better representation of the lower distribution tail. However it has the inconvenience of truncation at the upper bound. Fig. 9 compares the two distributions for 4.8 and $13.8 \mathrm{~mm}$ plates.

When the plate thickness is small the two distributions are almost similar. For thick plates, the Beta distribution presents an extended lower tail and fits better the observed behavior. Nevertheless, the Weibull distribution is still convenient for moisture scatter representation especially for high concentration region which is critical for practical design. 
Table 3 Influence of the parameter dispersion (thickness $=8.8 \mathrm{~mm}$ )

\begin{tabular}{lcccccc}
\hline $\begin{array}{l}\text { COV of } \\
\text { Thicknesss }\end{array}$ & $\begin{array}{c}\text { COV of } \\
D A 1\end{array}$ & $\begin{array}{c}\text { COV of } \\
D A 2\end{array}$ & $\begin{array}{c}\text { Mean } \\
\text { moisture }\end{array}$ & $\begin{array}{c}\text { Moisture } \\
\text { Standard } \\
\text { deviation }\end{array}$ & $\begin{array}{c}\text { Moisture } \\
\text { Kurstosis }\end{array}$ & $\begin{array}{c}\text { Moisture } \\
\text { Skewness }\end{array}$ \\
\hline 0.01 & 0.01 & 0.01 & 0.619 & 0.0055 & 0.09 & -0.14 \\
0.03 & 0.03 & 0.03 & 0.618 & 0.0172 & 0.67 & -0.56 \\
0.00 & 0.00 & 0.04 & 0.617 & 0.0266 & 5.01 & -1.58 \\
0.05 & 0.01 & 0.04 & 0.617 & 0.0250 & 2.20 & -1.07 \\
0.04 & 0.04 & 0.04 & 0.615 & 0.0259 & 2.88 & -1.20 \\
0.00 & 0.05 & 0.05 & 0.612 & 0.0395 & 5.60 & -1.94 \\
0.05 & 0.05 & 0.05 & 0.615 & 0.0353 & 4.69 & -1.68 \\
0.05 & 0.10 & 0.05 & 0.615 & 0.0355 & 4.90 & -1.71 \\
0.05 & 0.06 & 0.06 & 0.611 & 0.0480 & 6.38 & -2.11 \\
0.06 & 0.06 & 0.06 & 0.611 & 0.0482 & 6.27 & -2.10 \\
0.02 & 0.07 & 0.07 & 0.607 & 0.0620 & 7.10 & -2.32 \\
\hline
\end{tabular}

Table 4 Influence of the parameter dispersion (thickness $=13.8 \mathrm{~mm}$ )

\begin{tabular}{lcccccc}
\hline $\begin{array}{l}\text { COV of } \\
\text { Thickness }\end{array}$ & $\begin{array}{c}\text { COV of } \\
\text { DA1 }\end{array}$ & $\begin{array}{c}\text { COV of } \\
\text { DA2 }\end{array}$ & $\begin{array}{c}\text { Mean } \\
\text { moisture }\end{array}$ & $\begin{array}{c}\text { Moisture } \\
\text { Standard } \\
\text { deviation }\end{array}$ & $\begin{array}{c}\text { Moisture } \\
\text { Kurstosis }\end{array}$ & $\begin{array}{c}\text { Moisture } \\
\text { Skeweness }\end{array}$ \\
\hline 0.01 & 0.01 & 0.01 & 0.614 & 0.0094 & 0.45 & -0.68 \\
0.03 & 0.03 & 0.03 & 0.607 & 0.0354 & 2.79 & -1.57 \\
0.00 & 0.00 & 0.04 & 0.601 & 0.0541 & 5.01 & -2.04 \\
0.05 & 0.01 & 0.04 & 0.601 & 0.0534 & 3.43 & -1.79 \\
0.04 & 0.04 & 0.04 & 0.598 & 0.0540 & 3.35 & -1.73 \\
0.00 & 0.05 & 0.05 & 0.589 & 0.0761 & 3.05 & -1.77 \\
0.05 & 0.05 & 0.05 & 0.594 & 0.0696 & 3.24 & -1.80 \\
0.05 & 0.10 & 0.05 & 0.594 & 0.0699 & 3.24 & -1.79 \\
0.05 & 0.06 & 0.06 & 0.587 & 0.0870 & 2.91 & -1.77 \\
0.06 & 0.06 & 0.06 & 0.587 & 0.0872 & 2.90 & -1.77 \\
0.02 & 0.07 & 0.07 & 0.581 & 0.1031 & 2.48 & -1.71 \\
\hline
\end{tabular}

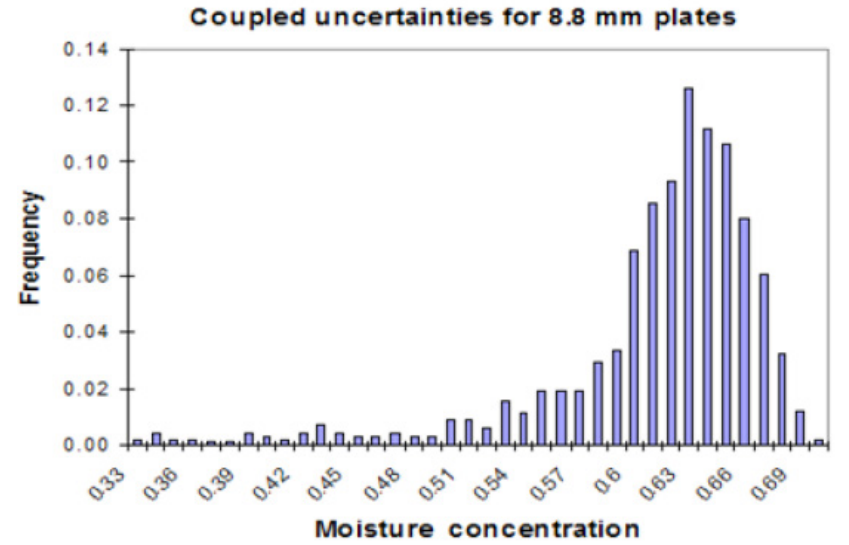

(a)

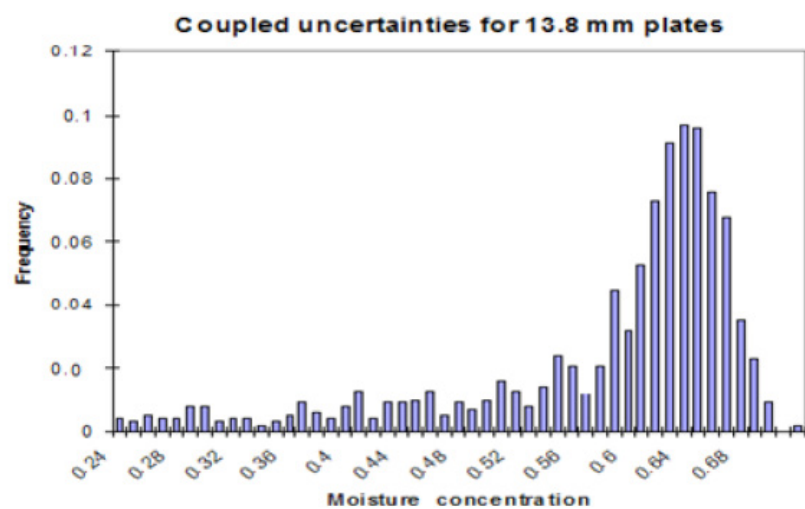

(b)

Fig. 8 Distribution of moisture concentration for different plate thicknesses; (a) Coupled uncertainties for 8.8 mm plates; (b) Coupled uncertainties for $13.8 \mathrm{~mm}$ plates 


\section{Conclusions}

In this work a numerical model is built for transient moisture concentration in composite plates in order to allow for uncertainty analyses. Under cyclic environmental conditions the model shows the influence of the temperature and plate thickness on the rate and the limit of concentration. From the reliability point of view, the obtained results underline the sensitivity of the moisture concentration to the scatter of the diffusion parameters $D A 1$ and $D A 2$. This observation leads to guide the test measurement on the parameter $D A 2$, rather than $D A 1$ or the thickness. Even with a very low coefficient of variation of $D A 2$ the scatter of moisture concentration is highly amplified. It is also shown that classical assumptions of normal distribution are not convenient for moisture modeling due to the very large skeweness of the distribution. The moisture can be appropriately represented by Weibull and Beta distributions where the parameters have been determined in order to be directly included in the reliability analysis of this kind of composite materials. In the near future and in our ongoing research this study can be extended to laminate plates and sandwich composites in random severe environments.

Table 5 Distribution parameters for moisture distribution fitting

\begin{tabular}{lccc}
\hline Distribution & $\begin{array}{c}\text { Thickness } \\
(\mathrm{mm})\end{array}$ & Parameters Kolmogorov-Smironov's test \\
\hline \multirow{3}{*}{ Weibull } & 4.8 & $\beta=18, \eta=0.63$ & 0.068 \\
& 8.8 & $\beta=16, \eta=0.63$ & 0.059 \\
& 13.8 & $\beta=12, \eta=0.635$ & 0.120 \\
Beta & 4.8 & $\alpha_{1}=18, \alpha_{2}=3.0, a=0, b=0.71$ & 0.133 \\
& 8.8 & $\alpha_{1}=14, \alpha_{2}=2.4, a=0, b=0.71$ & 0.120 \\
& 13.8 & $\alpha_{1}=8, \alpha_{2}=1.8, a=0, b=0.72$ & 0.106 \\
\hline
\end{tabular}

\section{References}

[1] Rocha, I. B. C. M., Raijmaekers, S., Nijssen, R. P. L., van der Meer, F. P., Sluys, L. J. "Experimental/numerical study of anisotropic water diffusion in glass/epoxy composites", IOP Conference Series: Materials Science and Engineering, 139, Article Number: 012044, 2016.

https:/doi.org/10.1088/1757-899X/139/1/012044

[2] Maxwell, A. S., Broughton, W. R., Dean, G., Sims, G. D. "Review of Accelerated Ageing Methods and Lifetime Prediction Techniques of Polymeric Materials", National Physical Laboratory, Teddington, UK, Rep. DEPC MPR 016, 2005.

[3] Griffis, C. A., Masumura, R. A., Chang, C. I. "Thermal Response of Graphite/Epoxy Composite Subjected to Rapid Heating", Journal of Composite Materials, 15(5), pp. 427-442, 1981. https://doi.org/10.1177/002199838101500503

\section{Acknowledgments}

The research received no specific grant from any funding agency in the public, commercial, or not-for- profit sector.

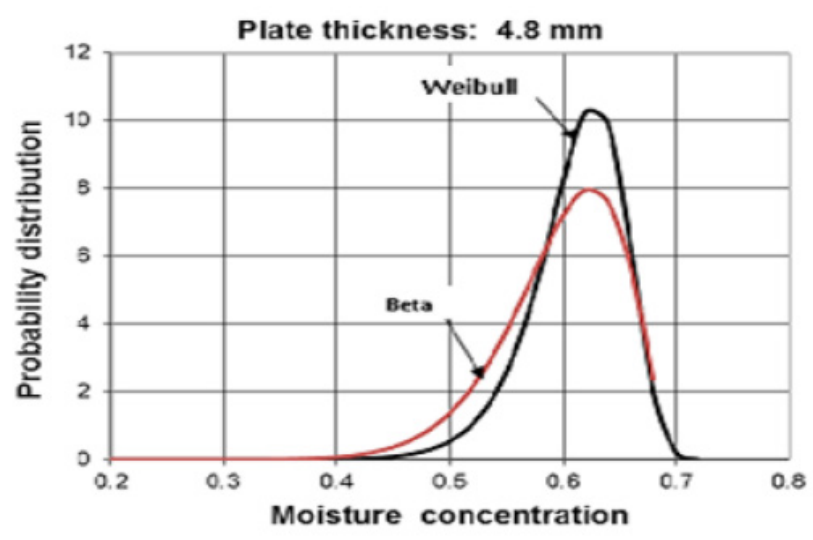

(a)

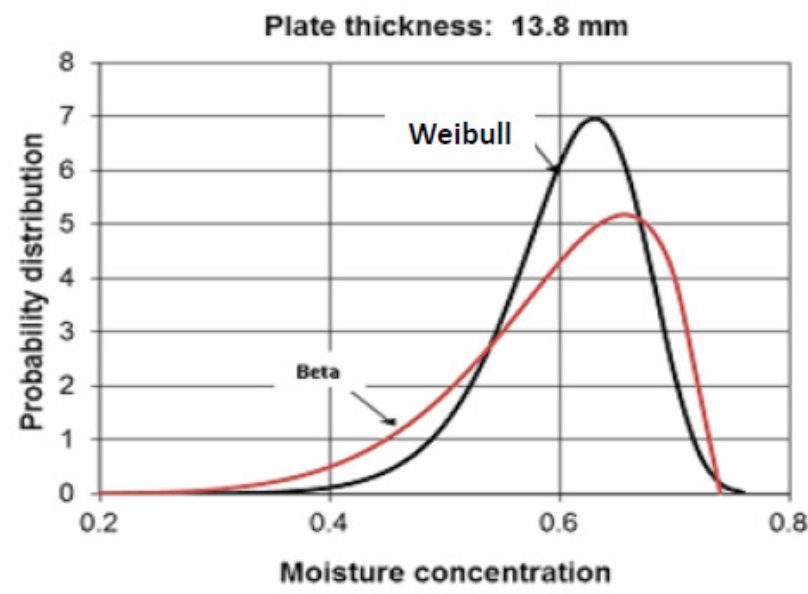

(b)

Fig. 9 Comparison of moisture models for plates with thickness 4.8 and $13.8 \mathrm{~mm}$; (a) Comparison of Moisture models for plates with thickness $4.8 \mathrm{~mm}$; (b) Comparison of Moisture models for plates with thickness $13.8 \mathrm{~mm}$

[4] Collings, T. A., Mead, D. L. "Effect of high temperature spikes on a carbone fiber-reinforced epoxy laminate", Composites, 19(1), pp. 61-66, 1988.

https://doi.org/10.1016/0010-4361(88)90545-9

[5] Davison, S. P. "Enviro-Mechanical Durability of Graphit/Epoxy Composite Materials", PhD Thesis, Virginia Polytechnic Institute and State University, 2003.

[6] Wang, S., Kowalik, D. P., Chung, D. D. L. "Effects of the temperature, humidity, and stress on the interlaminar interface of carbon fiber polymer-matrix composites, studied by contact electrical resistivity measurement", The Journal of Adhesion, 78(2), pp. 189-200, 2002.

https://doi.org/10.1080/00218460210384 
[7] Guzman, V. A., Brøndsted, P. "Effects of moisture on glass fiber-reinforced polymer composites", Journal of Composite Materials, 49(8), pp. 911-920, 2015.

https://doi.org/10.1177/0021998314527330

[8] Airale, A. G., Carello, M., Ferralis, A., Sisca, L. "Moisture effect on mechanical properties if polymeric composite materials", AIP Conference Proceedings, 1736(1), Article Number: 020020, 2016. https://doi.org/10.1063/1.4949595

[9] Almen, G. R., Byrens, R. M., MacKenzie, P. D., Maskell, R. K., McGrail, P. T., Sefton, M. S. "977 - a Family of New Toughened Epoxy matrices", In: 34th International SAMPE Symposium, Reno, NV, USA, 1989, pp. 259-270.

[10] Almen, G., MacKenzie, P., Malhotra, V., Maskell, R. "977: Characterization of a family of new toughened epoxy resins", 35th International SAMPE Symposium, Anaheim, CA, USA, 1990, pp. 419-431.

[11] Shen, C. H., Springer, G. S. "Effects of Moisture and Temperature on the Tensile Strength of Composite Materials", Journal of Composite Materials, 11(1), pp. 2-16, 1977. https://doi.org/10.1177/002199837701100102

[12] Shen, C. H., Springer, G. S. "Moisture Absorption and Desorption of Composite Materials", Journal of Composite Materials, 10(1), pp. 2-20, 1976. https://doi.org/10.1177/002199837601000101

[13] Boukhoulda, F. B., Guillaumat, L., Lataillade, J. L., Adda-Bedia, E., Lousdad, A. "Aging-impact coupling based analysis upon glass/polyester composite material in hygrothermal environment", Materials \& Design, 32(7), pp. 4080-4087, 2011. https://doi.org/10.1016/j.matdes.2011.03.009

[14] Mahmoudi, N., Hebbar, A., Zenasni, R., Lousdad, A. "Effect of Impact Directions, Fiber Orientation, and Temperature on Composite Material Strength", Journal of Composite Materials, 43(16), pp. 1713-1727, 2009. https://doi.org/10.1177/0021998309339634

[15] Springer, G. "Numerical procedures for the solutions of one-dimensional Fickian diffusion problems", In: Environmental effects on composite materials, Technomic Publishing Co., Westport, Connecticut, USA, 1981, pp. 166-199.

[16] Zhou, J., Lucas, J. P. "The effects of a water environment on anomalous absorption behavior in graphite/epoxy composites", Composites Science and Technology, 53(1), pp. 57-64, 1995. https://doi.org/10.1016/0266-3538(94)00078-6

[17] Huo, Z., Bheemreddy, V., Chandrashekhara, K., Brack, R. A. "Modelling of concentration-dependent moisture diffusion in hybrid fibre-reinforced polymer composites", Journal of Composite Materials, 49(3), pp. 321-333, 2015. https://doi.org/10.1177/0021998313519150

[18] Smith, L.V., Weitsaman, Y. J. "The immersed fatigue response of polymer composites", International Journal of Fracture, 82(1), pp. 31-42, 1996. https://doi.org/10.1007/BF00017862

[19] Chamis, C., Lark, R., Sinclair, J. "STP658 Integrated Theory for Predicting the Hygrothermomechanical Response of Advanced Composite Structural Components", In: Vinson, J. (ed.) Advanced Composite Materials-Environmental Effects, ASTM International, Conshohocken, PA, USA, 1978, pp. 160-192. https://doi.org/10.1520/STP34863S
[20] Kriz, R., Stinchcomb, W. "STP775 Effect of Moisture, Residual Thermal Curing Stresses, and Mechanical Load on the Damage Development in Quasi-Isotropic Laminates", In: Reifsnider, K. (ed.) Damage in Composite Materials: Basic Mechanisms, Accumulation, Tolerance, and Characterization, ASTM International, West Conshohocken, PA, USA, 1982, pp. 63-80. https://doi.org/10.1520/STP34321S

[21] Bradley, W. L., Grant, T. S. "The effect of the moisture absorption on the interfacial strength of polymeric matrix composites", Journal of Material Science, 30(21), pp. 5537-5542, 1995. https://doi.org/10.1007/BF00351570

[22] Han, M. H., Nairn, J. A. "Hygrothermal aging of polyimide matrix composite laminates", Composites Part A: Applied Science and Manufacturing, 34(10), pp. 979-986, 2003. https://doi.org/10.1016/S1359-835X(03)00154-4

[23] Browning, C., Husman, G., Whitney, J. "STP617 Moisture Effects in Epoxy Matrix Composites", In: Davis, J. Composite Materials: Testing and Design (Fourth Conference), ASTM International, Conshohocken, PA, USA, 1977, pp. 481-496. https://doi.org/10.1520/STP26961S

[24] Vaddadi, P., Nakamura, T., Singh, R. P. "Transient hygrothermal stresses in fiber reinforced composites: a heterogeneous characterization approach", Composites Part A: Applied Science and Manufacturing, 34(8), pp. 719-730, 2003. https://doi.org/10.1016/S1359-835X(03)00135-0

[25] Loos, A. C., Springer, G. S. "Moisture Absorption of GraphiteEpoxy Composites Immersed in Liquid an Humid Air", Journal of Composite Materials, 13(2), pp. 131-147, 1979. https://doi.org/10.1177/002199837901300205

[26] Adda-Bedia, E. A., Han, W. S., Verchery, G. "An asymptotic characterisation of the moisture diffusion in polymer matrix composites with cyclic environmental conditions", Composite Structures, 49(3), pp. 269-274, 2000. https://doi.org/10.1016/S0263-8223(00)00002-7

[27] Adda-Bedia, E., Han, W. S., Verchery, G. "Simplified methods for prediction of moisture diffusion in polymer matrix composites with cyclic environmental conditions", Polymers and Polymer Composites, 6(14), pp. 189-203, 1998.

[28] Verchery, G. "Designing with anisotropy, textile composite in building construction, Part 3", In: Hamelin, P., Verchery, G. (eds.) Mechanical behaviour, design and application, Pluralis, Paris, France, 1990, pp. 29-42.

[29] Tsai, S. W. "Composite Design", Think Composites, Dayton, OH, USA, 1988.

[30] Carter, H. G., Kibler, K. G. "Langmuir-Type Model for Anomalous Moisture Diffusion in Composite Resins", Journal of Composite Materials, 12(2), pp. 118-131, 1978. https://doi.org/10.1177/002199837801200201

[31] Hahn, H., Kim, R. "STP658 Swelling of Composite Laminates", In: Vinson, J. (ed.) Advanced Composite Materials-Environmental Effects, ASTM International, West Conshohocken, PA, USA, 1978, pp. $98-120$. https://doi.org/10.1520/STP34860S

[32] Delasi, R., Whiteside, J. "STP658 Effect of Moisture on Epoxy Resins and Composites", In: Vinson, J. (ed.) Advanced Composite Materials-Environmental Effects, ASTM International, Conshohocken, PA, USA, 1978, pp. 2-20. https://doi.org/10.1520/STP34855S 
[33] Highsmith, A., Stinchcomb, W., Reifsnider, K. "STP836 Effect of Fatigue Induced Defects on the Residual Response of Composite Laminates", In: Wilkins, D. (ed.) Effects of Defects in Composites Materials, ASTM International, West Conshohocken, PA, USA, 1984, pp. 194-216. https://doi.org/10.1520/STP30205S

[34] Crank, J. "The Mathematics of Diffusion", Clarendon Press, Oxford, UK, 1975.

[35] Shen, C. H., Springer; G. S. "Moisture Absorption and Desorption of Composite Materials", In: Springer, G. S. (ed.) Environmental Effects on Composite Materials, Technomic Publishing Co. Inc., CT, USA, 1981, pp. 15-33.
[36] Shen, C. H., Springer, G. S. "Moisture Absorption and Desorption of Composite Materials", Journal of Composite Materials, 10(1), pp. 2-20, 1976. https://doi.org/10.1177/002199837601000101

[37] Shirrell, C. "STP658 Diffusion of Water Vapor in Graphite/Epoxy Composites", In: Vinson, J. (ed.) Advanced Composite MaterialsEnvironmental Effects, ASTM International, 1978, pp. 21-42. https://doi.org/10.1520/STP34856S

[38] Lemaire, M., Chateauneuf, A., Mitteau, J. C. "Structural Reliability", ISTE Ltd., Newport Beach, CA, USA. 